\title{
Funções eco-hidrológicas das florestas nativas e o Código Florestal
}

LEANDRO REVERBERI TAMBOSI, ${ }^{I}$ MARIANA MORAIS VIDAL, ${ }^{I}$ SILVIO FROSINI DE BARROS FERRAZ III e JEAN PAUL METZGER ${ }^{\text {IV }}$

\section{Introdução}

A CRISE HÍDRICA que atinge a região Sudeste do Brasil tem proporções sem precedentes. Suas causas são múltiplas, em geral creditadas ao aumento da demanda por água em razão de crescimento populacional, ampliação do consumo per capita, falta de investimento em infraestrutura ou mesmo pelas mudanças climáticas. As consequências também são diversas, em particular sobre o saneamento básico, a saúde pública e sobre diferentes setores da economia, como a geração de energia e a produção de alimentos. Para lidar com essa crise no longo prazo, há basicamente duas ações que podem ser empreendidas: investimentos na infraestrutura de captação e distribuição de água; e investimentos na infraestrutura do "capital natural". Dentro desse capital, definido como o "estoque de recursos naturais que gera, a longo prazo, o suprimento de bens e serviços" (Costanza; Daly, 1992), estão as florestas nativas, cuja proteção em geral está associada com a regulação hidrológica e a manutenção da qualidade da água (Neary et al., 2009).

A presença de florestas nativas pode desempenhar diversas funções eco-hidrológicas, como a regulação da quantidade de água, o controle da erosão e aporte de sedimentos e, consequentemente, influenciando os parâmetros físico-químicos dos cursos d'água (Lima et al., 2013). Ainda mais relevante é que o papel das florestas no desempenho dessas funções depende da posição que elas ocupam no relevo, em particular se elas se encontram no topo de morro, nas encostas, ao longo dos cursos e reservatórios d'água, ou nos intervales (Falkenmark et al., 1999).

A proteção desse capital natural em propriedades privadas tem sido garantida no Brasil pelo Código Florestal Brasileiro (Lei Federal n.12.561/12), o qual define duas principais áreas de conservação: as Áreas de Preservação Permanente (APP), que protegem, entre outros, as florestas em topos de morro, encostas íngremes e ao longo de cursos d'água, e as Reservas Legais (RL), que legislam sobre a proteção de florestas nos intervales. Esse Código foi recentemente modificado, levando à redução na extensão de vegetação nativa a ser conservada em 
propriedades privadas, e para alguns autores essas modificações enfraqueceram seu papel na proteção das florestas, e logo na proteção dos recursos hídricos (Tundisi, 2014; Casatti, 2010).

Nesse contexto, este artigo procura analisar o papel das florestas e do Código Florestal na proteção dos recursos hídricos no Brasil. Mais especificamente, faremos uma síntese do conhecimento sobre a relação entre florestas e água, focando em particular sobre como as funções eco-hidrológicas das florestas se modificam em razão de sua posição no relevo, e uma análise crítica de como as mudanças recentes do Código Florestal podem impactar a efetividade desse capital natural em prover água em quantidade e qualidade no futuro.

\section{Funções eco-hidrológicas das florestas em topo de morro}

Nas bacias hidrográficas, a água que precipita nas áreas mais elevadas é transferida para as regiões mais baixas da bacia, contribuindo para a disponibilidade hídrica a jusante, onde a demanda por água e as fontes potenciais de poluição são geralmente mais pronunciadas, em razão da maior densidade populacional e da presença de atividades agrícolas e industriais (Falkenmark et al., 1999). Assim, as áreas mais baixas dependem muito da quantidade e da qualidade da água transferida das áreas mais elevadas da bacia hidrográfica, que podem ser consideradas como o reservatório natural do sistema (Falkenmark et al., 1999).

Dada a importância das regiões mais elevadas para o aporte hídrico de toda a bacia, as florestas localizadas nessas regiões desempenham um papel crítico, influenciando a quantidade, a forma e a qualidade da água que será transportada para o restante da bacia. As florestas localizadas nas regiões mais elevadas são particularmente importantes ao garantirem condições de infiltração da água no solo e consequente recarga dos aquíferos (Lima et al., 2013). Essas florestas nos topos de morros interceptam a água da chuva, ao mesmo tempo que a presença de serapilheira protege o solo do impacto direto das gotas de água, impedindo a erosão, a lixiviação e a compactação do solo (Giambelluca, 2002; Lima et al., 2013; Sayer, 2006). Assim, a presença de florestas nativas nos topos de morros é importante para a recarga dos aquíferos, diminuindo o volume de escoamento superficial pelas encostas, o que significa maior estabilidade e menores riscos de deslizamentos ou escorregamentos de massa (Silva et al., 2011).

Não apenas a presença, mas também as condições das florestas são determinantes para que haja maior interceptação de chuva e infiltração efetiva de águas pluviais no solo (Ferraz et al., 2014). A existência de um dossel denso, a presença de sub-bosque e o alto teor de matéria orgânica no solo são exemplos de características de florestas que aumentam a sua capacidade em promover a infiltração da água no solo (Lima et al., 2013). Por outro lado, florestas degradadas, que não possuem dossel ou apresentam várias clareiras, e que têm pouca estratificação da vegetação e baixo conteúdo de serapilheira e matéria orgânica no solo, acabam tendo menor capacidade de interceptação de água da chuva e de infiltração, aumentando o escoamento superficial e o potencial erosivo das chuvas. 
O novo Código Florestal alterou os parâmetros de amplitude altimétrica, declividade e linha de base que delimitam as APP em topo de morro. Em síntese, houve uma restrição nas áreas que devem ser definidas como topo de morro, considerando agora apenas morros com mais de $100 \mathrm{~m}$ de amplitude altimétrica (ante $50 \mathrm{~m}$ na legislação anterior) a contar do fundo de vale, com inclinação média superior a $25^{\circ}$ ( $17^{\circ}$ antes). Anteriormente, a delimitação da cota de APP de topo de morro era realizada considerando dois terços da altura com relação ao pico mais baixo da linha de cumeada e, atualmente, é delimitada a partir do pico mais alto da linha de cumeada. A redução nas APP em topo de morro está estimada em $87 \%$ no conjunto do território brasileiro (Soares-Filho et al., 2014), indicando uma perda generalizada de proteção deste tipo de ambiente (Silva et al., 2012), o que pode representar grandes modificações no ciclo hidrológico, interferindo em processos como infiltração e escoamento superficial das águas (Varjabedian; Mechi, 2013).

Além da efetiva diminuição das áreas consideradas APP em topo de morro, o novo Código Florestal admite que nas áreas rurais consolidadas sejam mantidas "atividades florestais, culturas de espécies lenhosas, perenes ou de ciclo longo, bem como da infraestrutura física associada ao desenvolvimento de atividades agrossilvipastoris". Segundo a lei, as áreas rurais consolidadas correspondem a "imóveis rurais com ocupação antrópica preexistente a 22 de julho de 2008, com edificações, benfeitorias ou atividades agrossilvipastoris". Dessa maneira, a nova legislação exime diversos proprietários rurais da necessidade de restaurar as áreas em topos de morros quando essas já apresentarem uso agrícola anterior a julho de 2008. Ademais, permite-se que atividades agrossilvipastoris, que compactam o solo e favorecem a erosão e assoreamento dos rios, sejam estabelecidas nessas áreas (Silva et al., 2012).

Tanto as alterações na delimitação das APP em topo de morro, reduzindo a área protegida, quanto a anistia concedida aos proprietários que desmataram essas áreas, retirando a exigência de restauração das mesmas, são medidas que prejudicam o funcionamento e a integridade das bacias hidrográficas, na medida em que comprometem as funções hidrológicas da vegetação nativa em topos de morros, relacionadas principalmente à infiltração de águas pluviais e consequente recarga de aquíferos. Além das consequências sobre os recursos hídricos, a redução das APP em topos de morros afeta a preservação dos solos e constitui uma ameaça à manutenção da biodiversidade (Silva et al., 2011).

\section{Funções eco-hidrológicas das florestas em encostas}

As encostas de morros e montanhas são mais sujeitas à força da gravidade, cujo efeito acelera o movimento da água de percolação ou da água em escoamento superficial, sendo regiões com maior tendência a movimentos de massas de solos e de fragmentos de rocha (Silva et al., 2011). A presença de vegetação nas encostas tem papel importante na interceptação das chuvas, proteção e estruturação do solo. A vegetação nas encostas também atua como barreira para o 
fluxo hídrico, promovendo a redução da velocidade do escoamento superficial, e consequentemente da erosão. Os deslizamentos nessas áreas são causados por fatores naturais, mas podem ser agravados pela remoção da cobertura e desestruturação do solo, tanto em ambientes urbanos quanto em rurais (Marston, 2010). Assim, a presença da vegetação aumenta a estabilidade das encostas.

As APP de encosta são definidas no Código Florestal como as áreas com declividade superior a $45^{\circ}$. Essa definição manteve-se inalterada no novo Código Florestal. Apesar das APP de encosta estarem voltadas para as áreas com maior risco de erosão e deslizamentos, elas se restringem a regiões muito íngremes. Áreas com declividades inferiores já apresentam alto risco de movimentos de massa e erosão. De modo geral, terrenos com declividade superior a $25^{\circ}$, que tiveram sua vegetação natural retirada por atividade humana, têm risco alto de repetidos processos de deslizamentos e escorregamentos de massa, como os observados em áreas de declividade entre $18^{\circ}$ e $37^{\circ}$ no Rio de Janeiro (Fernandes et al., 2001) e entre $20^{\circ}$ e $40^{\circ}$ em Cubatão (Lopes et al., 2007).

Em razão do alto risco de erosão em declividades inferiores a $45^{\circ}$, o antigo Código Florestal determinava, em seu artigo 10, que não seria "permitida a derrubada de florestas situadas em áreas de inclinação entre 25 a 45 graus, só sendo nelas tolerada a extração de toros, quando em regime de utilização racional, que vise a rendimentos permanentes". No entanto, o novo Código Florestal estabelece, em seu artigo 11 , que "em áreas de inclinação entre $25^{\circ} \mathrm{e}$ $45^{\circ}$, serão permitidos o manejo florestal sustentável e o exercício de atividades agrossilvipastoris, bem como a manutenção da infraestrutura física associada ao desenvolvimento das atividades, observadas boas práticas agronômicas, sendo vedada a conversão de novas áreas, excetuadas as hipóteses de utilidade pública e interesse social”. Assim, essa mudança na legislação deixa desprotegidas áreas especialmente susceptíveis a escorregamentos de solo, que é o caso das encostas entre $25^{\circ}$ e $45^{\circ}$, pois permite o estabelecimento de atividades que podem provocar a erosão e aumentar os riscos de deslizamentos, como o pastoreio (Silva et al., 2012).

De forma similar às APP de topos de morro, as áreas ocupadas antes de 22 de julho de 2008 em APP de encosta também foram anistiadas, e assim não precisam ser restauradas. Dessa forma, áreas com alto risco de deslizamentos e com grande potencial de erosão poderão manter suas atividades agrossilvipastoris e as estruturas associadas a elas, aumentando os riscos de desastres naturais com vítimas (Coutinho et al., 2013), além de aumentar a erosão e o carreamento de sedimentos, promovendo o assoreamento e a contaminação dos corpos d'água por insumos agrícolas (Tundisi; Tundisi, 2010; Tundisi, 2014).

\section{Funções eco-hidrológicas das florestas em áreas ripárias}

A região localizada nas margens dos corpos d'água é considerada uma zona de transição ou ecótono entre os ecossistemas terrestres e aquáticos que influencia diretamente os parâmetros físico-químicos e biológicos dos corpos d'água. 
A presença de vegetação, e em particular de florestas, nessas áreas ribeirinhas ou ripárias, provê uma série de funções eco-hidrológicas. Primeiro, essa vegetação propicia o microclima adequado para o funcionamento do ambiente aquático, especialmente em riachos ou corpos d'água menores, reduzindo a incidência de raios solares e aumentando a estabilidade térmica do ambiente aquático. Além disso, a interação da vegetação com o riacho propicia a entrada de materiais alóctones, fundamentais para a manutenção da cadeia alimentar e formação de habitats aquáticos (Casatti, 2010; Paula et al., 2013). Essas funções da vegetação ripária garantem uma maior estabilidade em diferentes parâmetros físicoquímicos da água e reduzem o risco de eutrofização, favorecendo a manutenção da qualidade da água e reduzindo possíveis gastos com tratamento para uso humano (Casatti, 2010; Tundisi; Tundisi, 2010; Tundisi, 2014).

Segundo, a vegetação ripária também possibilita uma maior estabilidade dos canais pela proteção dos solos nas margens dos rios, reduzindo a erosão dos canais e diminuindo o assoreamento dos corpos d'água (Naiman et al., 2000). Além de aumentar a estabilidade do canal, a presença de vegetação ripária, aliada à presença de vegetação em outras áreas da bacia, equilibra o fluxo superficial e subsuperficial de água, reduzindo a variação do fluxo hídrico em razão de eventos climáticos, regulando melhor a vazão em épocas de seca e eventos de cheias (Walter et al., 2000; Lima et al., 2012). A função reguladora da região ripária é explicada pela sua dinâmica de saturação do solo e que a torna muito sensível à ocorrência de contaminação direta do corpo hídrico se manejada inadequadamente pela atividade agrícola ou qualquer uso intensivo (Walter et al, 2000).

Terceiro, a vegetação ripária pode atuar como uma barreira para nutrientes e contaminantes que são carreados desde as áreas mais altas da bacia em direção aos leitos dos corpos d'água (Falkenmark et al., 1999; Allan, 2004). No entanto, é importante salientar que apesar de a vegetação ripária reduzir a entrada desse material nos corpos d'água, o uso de técnicas de conservação dos solos em toda a bacia e a presença de florestas em áreas de intervales (ver adiante) também são necessários para tornar esse processo mais efetivo, reduzindo assim de forma mais substancial o aporte de poluentes aos rios e controlando os processos erosivos.

Finalmente, a presença de florestas nas margens dos rios também atua na manutenção da biodiversidade terrestre, pois essas áreas funcionam como corredores ou áreas de hábitat para diversas espécies de animais e plantas (Metzger et al., 1997; Keuroghlian; Eaton, 2008; Martensen et al., 2008; Metzger, 2010).

A efetividade dessas faixas de vegetação ripária para prover todas essas funções eco-hidrológicas depende de vários fatores, entre eles o estado de conservação e o tipo de vegetação presente, bem como a largura da faixa preservada (Silva et al., 2011), e a largura ideal da faixa de vegetação ripária vai variar em razão das características geomorfológicas das microbacias (Lima et al., 2012).

A delimitação das APP ao longo dos cursos d'água sofreu importantes alterações com a nova versão do Código Florestal. A principal mudança ocorrida, 
que atinge todos os corpos d'água, refere-se ao ponto inicial para delimitação da faixa marginal aos cursos d'água. Na versão do Código Florestal de 1965, a APP deveria ser delimitada a partir do maior leito sazonal dos rios, incluindo as áreas de inundação nas épocas de cheias, mas na versão do Código Florestal de 2012, a APP é delimitada a partir do leito regular do rio. Essa mudança tem um duplo efeito: i) ela reduz a extensão da largura do rio (que antigamente incluía a planície de inundação anual), fazendo que a largura da faixa de proteção possa ser reduzida; e ii) ela reduz a proteção das áreas de várzea, principalmente em rios com amplas planícies de inundação (como no caso de muitos rios no Pantanal e na Amazônia), pois com o novo Código as APP ripárias irão proteger apenas uma parte dessas áreas de várzea. Isso é particularmente grave, pois as várzeas desempenham importantes funções ecossistêmicas e hidrológicas. Elas dissipam as forças erosivas do escoamento superficial de águas pluviais, controlam as enchentes, facilitam a deposição de sedimentos suspensos na água, além de constituírem sítios de alimentação e abrigo para muitas espécies (Silva et al., 2012).

Outra diferença importante entre as versões do Código Florestal diz respeito à proteção das nascentes. $\mathrm{O}$ texto do novo Código Florestal exclui a proteção de nascentes e olhos d'água intermitentes, contemplando apenas as nascentes perenes, e exclui as faixas marginais de cursos d'água efềmeros, o que ameaça diversas nascentes e cursos d'água, e por consequência coloca em risco a proteção dos recursos hídricos, em particular em áreas mais susceptíveis, que têm clima mais seco.

Outra importante modificação com relação às APP ripárias está relacionada à necessidade de restauração de APP ocupadas por atividades antrópicas. Anteriormente, toda APP ocupada deveria ser restaurada com vegetação nativa. Entretanto, no novo Código Florestal, as APP com uso consolidado antes de 22 de julho de 2008 terão que ser restauradas, porém não em toda a sua extensão. A extensão a ser restaurada varia de acordo com o tamanho da propriedade, o tipo de APP (ao redor de nascente, vereda, lagos e lagoas ou rios), e a largura do rio. Segundo essa regra, a extensão a ser restaurada no entorno de rios, lagoas, lagos e veredas é reduzida à medida que diminui o tamanho das propriedades, havendo ainda um teto máximo de restauração de $10 \%$ em propriedades inferiores a dois módulos fiscais e de $20 \%$ em propriedades entre dois e quatro módulos fiscais (Lei Federal n.12.561/12).

Dessa maneira, a recuperação das funções das APP por estratégias de restauração ao longo dos corpos d'água pode ficar comprometida em razão da redução das áreas a serem restauradas. Essa redução, aliada à não exigência de restauração das APP de topo de morro e encosta, diminui o potencial dessas áreas em prover todos os serviços eco-hidrológicos aqui mencionados, que são essenciais tanto para a provisão quanto para a qualidade de água para uso humano. 


\section{Funções eco-hidrológicas das florestas nos intervales}

Apesar de as áreas situadas fora das APP, aqui chamadas de intervales, não serem tão sensíveis à ausência da cobertura florestal nativa, elas também têm funções eco-hidrológicas relevantes e complementares àquelas das APP. Em particular, a cobertura florestal nessas áreas contribui para a interceptação da água da chuva, infiltração das águas pluviais no solo, reduzindo assim o volume de escoamento superficial e a consequente erosão dos solos, e funciona também como barreira auxiliar para nutrientes e contaminantes. Pode ainda atuar como zonas-tampão de proteção das APP. Ademais, as florestas de intervales constituem áreas de hábitat para diversas espécies, e por estarem em condições abióticas distintas das APP, em termos de posição no relevo, tipo de solo, influência de cheias, susceptibilidade a deslizamentos, dentre outros, elas têm potencialmente uma estrutura e composição florística e faunística distintas daquelas encontradas nas APP (Metzger, 2010). Assim como ocorre nas APP, a efetividade da vegetação de intervales em prover as diversas funções eco-hidrológicas vai depender do tipo e da qualidade desta vegetação e das características da bacia.

A vegetação de intervales é basicamente protegida no Código Florestal por meio das Reservas Legais (RL). Apesar de a definição de RL não ter sido alterada no novo Código Florestal, duas mudanças importantes fizeram que na prática houvesse uma redução na área efetiva de RL dentro das propriedades. Na versão atual do código, é possível computar as APP no cálculo da área a ser destinada como RL, definida como porcentagens da propriedade de acordo com o bioma e fisionomia em que ela se encontra (na Amazônia Legal, 80\% em área de cobertura florestal, $35 \%$ em cerrado e $20 \%$ em campos gerais, e nas demais regiões do país, 20\%). Essa porcentagem refere-se agora à área total da propriedade e não à área útil (área da propriedade descontada a área de APP). Além disso, em propriedades de até quatro módulos fiscais, a RL será representada pela vegetação existente até 22 de julho de 2008. Como as RL apresentam o maior passivo ambiental do setor agropecuário brasileiro (Soares-Filho, 2013), isso significa uma redução substancial nas exigências de conservação de vegetação de intervales. Com essas mudanças, a porcentagem total de vegetação requerida pela nova lei nas propriedades particulares é expressivamente inferior à exigida pelo Código Florestal antigo.

Essa redução na área de vegetação de intervales exigida por lei tem por consequência uma menor flexibilidade no uso dessa cobertura para auxiliar na otimização das funções eco-hidrológicas das microbacias. Em particular, nas microbacias de relevo mais acidentado, as RL poderiam ser alocadas em posições que apresentam alta susceptibilidade a erosão, devido à maior declividade (por exemplo, entre 25 e 45 graus), e ajudar assim na redução do potencial de erosão. No caso de microbacias em regiões mais planas, com áreas de várzeas mais extensas, que não são plenamente protegidas pela nova delimitação de APP ripária, a RL poderia ser alocada com o objetivo de complementar o papel da vegetação 
de APP ripária, aumentando a quantidade de vegetação em áreas de várzea ou de planícies de inundação, e assegurando assim uma maior proteção aos cursos e corpos d'água.

Outra alteração importante refere-se à forma de compensação ou restauração da RL. No Código Florestal anterior, caso um proprietário não possuísse a quantidade de RL necessária no interior de sua propriedade, ele poderia compensar em uma área de vegetação nativa existente ou restaurar uma área fora de sua propriedade, desde que localizada na mesma microbacia. Porém, com a alteração do Código, a compensação das RL agora pode ser realizada em um mesmo bioma, permitindo que as áreas sejam compensadas em regiões a quilômetros de distância das propriedades, em terrenos mais baratos, onde ainda podem existir áreas com vegetação contínua. Assim a compensação das RL deixa de exercer as funções eco-hidrológicas na mesma microbacia em que está a propriedade. Ademais, a nova legislação permite que até $50 \%$ da área da RL seja composta por espécies exóticas, desde que intercaladas com espécies nativas. Porém, o uso de espécies exóticas pode comprometer sua função de conservação da biodiversidade (Metzger, 2010), além de não assegurar a plena restauração de suas funções eco-hidrológicas que dependem de uma estrutura florestal preservada complexa para garantir a proteção e estruturação dos solos (Lima et al., 2013) e servir como fonte de recursos para a biota aquática (Casatti, 2010).

Finalmente, vale ressaltar que a restauração das áreas florestais é atualmente viável graças ao avanço do conhecimento cientifico e tecnológico (Rodrigues et al., 2009). Novas técnicas de restauração da RL podem ser alternativas viáveis de diversificação da produção, com retorno econômico significativo. É possível, por exemplo, usar as áreas de menor aptidão agrícola e incorporar o conceito de manejo sustentável de espécies nativas para a produção de madeiras e fibras, de compostos medicinais, ou mesmo para a exploração de espécies frutíferas nativas e outras permitidas pela legislação.

Em suma, as alterações que resultaram na redução da área de $\mathrm{RL}$ e na possibilidade de deslocamento das RL para outras microbacias reduziram a efetividade da vegetação de intervales em prover funções eco-hidrológicas e a possibilidade de utilização dessa vegetação para aprimorar a gestão hídrica e proteger as regiões mais sensíveis da microbacia.

\section{Considerações finais}

A cobertura florestal ou de vegetação nativa situada em diferentes posições de relevo tem diferentes funções eco-hidrológicas, ora mais voltadas para a recarga de aquíferos (topos de morro), ora para a redução do escoamento superficial e contenção de processos erosivos (nas encostas), ou ainda para a proteção de corpos d'água (áreas ripárias), ou então como elementos auxiliares em todas essas funções (nos intervales). Como essas funções são complementares, para que uma paisagem ou uma bacia tenha uma estrutura adequada para a provisão de água em quantidade e qualidade, não basta estabelecer uma quantidade 
mínima de vegetação nativa para o conjunto da área considerada - é necessário haver cobertura vegetal adequada em cada posição do relevo, para que todas as funções eco-hidrológicas sejam devidamente prestadas. Nesse sentido, não é aconselhado compensar indiscriminadamente áreas florestais situadas em diferentes posições do relevo.

As alterações do Código Florestal promoveram uma redução da vegetação protegida em todas as posições do relevo, ora por mudanças nos critérios de delimitação (como no caso dos topos de morro e das áreas ripárias, ou pela flexibilização do cômputo de RL), ora por terem reduzido o passivo ambiental, consolidando a maior parte dos desmatamentos ilegais realizados antes de 22 de julho de 2008. No âmbito de todo o país, as alterações provocaram uma redução de 58\% no passivo ambiental, sendo 22 milhões de hectares para adequação de RL e oito milhões de hectares para adequação de APP (Soares-Filho, 2013). A extensão das implicações dessas mudanças ainda é incerta e irá variar de uma região para a outra.

Diante do atual cenário de aumento da demanda por recursos hídricos e de maior frequência de eventos climáticos extremos, que levam a importantes oscilações temporais na pluviosidade, é necessário não apenas manter o potencial de nossas paisagens em prover recursos hídricos, mas é fundamental aumentar esse potencial e assegurar uma regularidade nessa oferta. Infelizmente, as mudanças do Código Florestal vêm na contramão do que seria necessário para uma adequada gestão desses recursos.

Para reverter, em longo prazo, esse quadro desfavorável, será necessário o estabelecimento de novas políticas públicas que valorizem o capital natural e incentivem a restauração de áreas degradadas. Essas ações devem contemplar a cobertura florestal em todas as posições de relevo, para favorecer todo o rol de funções eco-hidrológicas, propiciando assim as condições necessárias para a oferta de água em quantidade e qualidade, com a devida regularidade, o que é essencial para garantir uma maior segurança hídrica para a população brasileira.

\section{Referências}

ALLAN, J. D. Landscapes and riverscapes: the influence of land use on stream ecosystems. Annual Review of Ecology, Evolution and Systematics, v.35, p.257-84, 2004.

CASATTI, L. Alterações no Código Florestal Brasileiro: impactos potenciais sobre a ictiofauna. Biota Neotropica, v.10, n.4, p.31-4, 2010.

COSTANZA, R.; DALY, H. E. Natural Capital and Sustainable Development. Conservation Biology, v.6, n.1, p.37-46, 1992.

COUTINHO, M. P. et al. O Código Florestal Atual (Lei Federal n.12.651/2012) e suas implicações na prevenção de desastres naturais. Sustentabilidade em Debate, v.4, n.2, p.237-56, 2013.

FALKENMARK, M. et al. Water, a reflection of land use: options for counteracting 
land and water mismanagement. Stockholm, Sweden: Swedish Natural Science Research Council, 1999. 128p.

FERNANDES, N. F. et al. Condicionantes geomorfológicos dos deslizamentos nas encostas: avaliação de metodologias e aplicação de modelo de previsão de áreas susceptíveis. Revista Brasileira de Geomorfologia, v.2, n.1, p.51-71, 2001.

FERRAZ, S. F. B. et al. How good are tropical forest patches for ecosystem services provisioning. Landscape Ecology, v.29, n.2, p.187-200, 2014.

GIAMBELLUCA, T. W. Hydrology of altered tropical forest. Hydrological Processes, v.16, n.8, p.1665-9, 2002.

KEUROGHLIAN, A.; EATON, D. P. Importance of rare habitats and riparian zones in a tropical forest fragment: Preferential use by Tayassu pecari, a wide-ranging frugivore. Journal of Zoology, v.275, n.3, p.283-93, 2008.

LIMA, W. de P. et al. Forest plantations and water consumption: a strategy for hydrosolidarity. International Journal of Forestry Research, New York, 2012. Disponível em: <http://dx.doi.org/10.1155/2012/908465>. Acesso em: 15 jun. 2015.

LIMA, W. de P.; FERRAZ, S. F. de B.; FERRAZ, K. M. P. M. Interações bióticas e abióticas na paisagem: uma perspectiva eco hidrológica. In: CALIJURI, M. do C.; CUNHA, D. G. F. (Ed.) Engenharia ambiental: conceitos, tecnologia e gestão. Rio de Janeiro: Elsevier, 2013. p.215-44.

LOPES, E. S. S. et al. Inventário de escorregamentos naturais em banco de dados geográfico - análise dos fatores condicionantes na região da Serra de Cubatão - SP. In: XIII SIMPÓSIO BRASILEIRO DE SENSORIAMENTO REMOTO. Florianópolis, 2007. Anais... Florianópolis, Inpe, 2007. p.2785-96.

MARSTON, R. A. Geomorphology and vegetation on hillslopes: Interactions, dependencies, and feedback loops. Geomorphology, v.116, n.3-4, p.206-17, 2010.

MARTENSEN, A. C.; PIMENTEL, R. G.; METZGER, J. P. Relative effects of fragment size and connectivity on bird community in the Atlantic Rain Forest: Implications for conservation. Biological Conservation, v.141, n.3, p.2184-92, 2008.

METZGER, J. P. O Código Florestal tem base científica? Natureza é Conservação, v.8, n.1, p.92-9, 2010.

METZGER, J. P.; BERNACCI, L. C.; GOLDENBERG, R. Pattern of tree species diversity in riparian forest fragments with different widths (SE Brazil). Plant Ecology, v.133, n.2, p.135-52, 1997.

NAIMAN, R. J.; BILBY, R. E.; BISSON, P. A. Riparian Ecology and Management in the Pacific Coastal Rain Forest. BioScience, v.50, n.11, p.996-1011, 2000.

NEARY, D. G.; ICE, G. G.; JACKSON, C. R. Linkages between forest soils and water quality and quantity. Forest Ecology and Management, v.258, n.10, p.2269-2281, 2009.

PAULA, F. R. et al. Influence of forest cover on in-stream large wood in an agricultural landscape of southeastern Brazil: a multi-scale analysis. Landscape Ecology, v.28, n.1, p.13-27, 2013.

RODRIGUES, R. R. et al. On the restoration of high diversity forests: 30 years of experience in the Brazilian Atlantic Forest. Biological Conservation, v.142, n.6, p.1242-51, 2009. 
SAYER, E. J. Using experimental manipulation to assess the roles of leaf litter in the functioning of forest ecosystems. Biological Reviews, v.81, n.1, p.1-31, 2006.

SILVA, J. A. A. et al. O Código Florestal e a Ciência: contribuições para o diálogo. São Paulo: Sociedade Brasileira para o Progresso da Ciência, SBPC; Academia Brasileira de Ciências, ABC, 2011. 124p.

SILVA, J. A. A. et al. O Código Florestal e a Ciência: contribuições para o diálogo. 2.ed. São Paulo: Sociedade Brasileira para o Progresso da Ciência, SBPC; Academia Brasileira de Ciências, ABC, 2012. 294p.

SOARES-FILHO, B. S. Impacto da revisão do Código Florestal: como viabilizar o grande desafio adiante? Brasília: Subsecretaria de Desenvolvimento Sustentável. Secretaria de Assuntos Estratégicos, Governo Federal, Brasil, 2013. 28p.

SOARES-FILHO, B. S. et al. Cracking Brazil's Forest Code. Science, v.344, n.6182, p.363-4, 2014.

TUNDISI, J. G. (Ed.) Recursos hidricos no Brasil: problemas, desafios e estratégias para o futuro. Rio de Janeiro: Academia Brasileira de Ciências, 2014. 76p.

TUNDISI, J. G.; TUNDISI, T. M. Impactos potenciais das alterações do Código Florestal nos recursos hídricos. Biota Neotropica, v.10, n.4, p.67-75, 2010.

VARJABEDIAN, R.; MECHI, A. As APPs de topo de morro e a Lei 12.651/12. In: $14^{\circ}$ CONGRESSO BRASILEIRO DE GEOLOGIA DE ENGENHARIA E AMBIENTAL. Rio de Janeiro. 2013. Anais... Associação Brasileira de Geologia de Engenharia e Ambiental, Rio de Janeiro, 2013.

WALTER, M. T. et al. Hydrologically sensitive areas: Variable source area hydrology implications for water quality risk assessment. Journal of Soil and Water Conservation, v.55, n.3, p.277-84, 2000.

RESUMO - A existência de uma relação entre cobertura florestal e provisão de água é foco de estudos há décadas, especialmente no que diz respeito às funções eco-hidrológicas da vegetação situada em diferentes posições do relevo. Neste artigo, fazemos uma síntese da literatura sobre essas funções e analisamos como as mudanças recentes no Código Florestal Brasileiro podem afetar essas relações. Mostramos que a posição no relevo da vegetação nativa altera as funções eco-hidrológicas que elas exercem, sendo mais voltadas para a recarga de aquíferos, ou para a redução do escoamento superficial e contenção de processos erosivos, ou para a proteção de corpos d'água, ou ainda como elementos auxiliares em todas essas funções. Assim, é necessário haver cobertura vegetal em cada posição do relevo, para garantir a provisão das funções eco-hidrológicas no conjunto de uma bacia. O novo Código Florestal, ao promover uma redução da proteção da vegetação em todas as posições do relevo, deverá reduzir a capacidade de provisão de água em qualidade e regularidade compatíveis com as demandas futuras. Para reverter essa situação, é necessário estabelecer novas políticas públicas que promovam a manutenção ou a restauração da vegetação natural em todas as posições do relevo.

PALAVRAS-CHAVE: Florestas nativas, Funções eco-hidrológicas, Código Florestal Brasileiro, Recursos hídricos. 
ABSTRACT - The relationship between forest cover and water supply has been studied for decades, especially in regard to the ecohydrological functions provided by native vegetation. In this study, we present a literature synthesis of the different ecohydrological functions provided by the forests and how the provision of these functions may be affected by recent changes in the Brazilian Forest Code. Depending on the location in the watershed, the functions provided by the forests can be more associated to aquifer recharge, to the reduction of runoff and erosion, to the protection of water bodies, or complementing all these functions. Thus, forest cover is needed in different regions of the watersheds to ensure the provision of all ecohydrological functions. The new Brazilian Forest Code reduced the legal protection of vegetation in all the different regions of the watersheds, and may reduce provision of water resources in adequate quality and regularity needed to supply future demands. To mitigate this situation, it is necessary to establish new public policies to maintain or restore native vegetation in different regions of the watersheds.

KEYWORDS: Native forests, Ecohydrological functions, Brazilian Forest Code, Water resources.

Leandro Reverberi Tambosi é doutor em Ecologia pela Universidade de São Paulo e atualmente é pós-doutorando no departamento de Ecologia da Universidade de São Paulo.@-letambosi@yahoo.com.br

Mariana Morais Vidalé doutora em Ecologia pela Universidade de São Paulo.

@ - marimvidal@yahoo.com.br

Silvio Frosini de Barros Ferraz é doutor em Recursos Florestais pela Universidade de São Paulo. É professor do Departamento de Ciências Florestais da Escola Superior de Agricultura Luiz de Queiroz da Universidade de São Paulo, Piracicaba.

@ - silvio.ferraz@usp.br

Jean Paul Metzger é doutor em Ecologia de Paisagens pela Universidade Paul Sabatier de Toulouse, França. É professor titular do Departamento de Ecologia do Instituto de Biociências da Universidade de São Paulo. @-jpm@ib.usp.br

Recebido em 19.6.2015 e aceito em 6.7.2015.

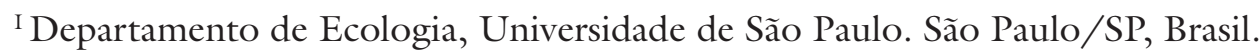

II Instituto de Biociências, Universidade de São Paulo. São Paulo/SP, Brasil.

III Escola Superior de Agricultura Luiz de Queiroz, Universidade de São Paulo. Piracicaba/SP, Brasil.

IV Instituto de Biociências, Universidade de São Paulo. São Paulo/SP, Brasil. 